\title{
Ensemble yield simulations: crop and climate uncertainties, sensitivity to temperature and genotypic adaptation to climate change
}

\author{
Andrew Juan Challinor ${ }^{1, *}$, Tim Wheeler ${ }^{2}$, Debbie Hemming ${ }^{3}$, H. D. Upadhyaya ${ }^{4}$ \\ ${ }^{1}$ Institute for Climate and Atmospheric Science, School of Earth and Environment, The University of Leeds, Leeds LS2 9JT, UK \\ ${ }^{2}$ Walker Institute, Agriculture Building, University of Reading, Earley Gate, Reading RG6 6AR, UK \\ ${ }^{3}$ Met Office Hadley Centre for Climate Change, Met Office, FitzRoy Road, Exeter EX1 3PB, UK \\ ${ }^{4}$ International Crops Research Institute for the Semi-Arid Tropics (ICRISAT), Patancheru 502 324, Andhra Pradesh, India
}

\begin{abstract}
Estimates of the response of crops to climate change rarely quantify the uncertainty inherent in the simulation of both climate and crops. We present a crop simulation ensemble for a location in India, perturbing the response of both crop and climate under both baseline (12 720 simulations) and doubled- $\mathrm{CO}_{2}$ (171720 simulations) climates. Some simulations used parameter values representing genotypic adaptation to mean temperature change. Firstly, observed and simulated yields in the baseline climate were compared. Secondly, the response of yield to changes in mean temperature was examined and compared to that found in the literature. No consistent response to temperature change was found across studies. Thirdly, the relative contribution of uncertainty in crop and climate simulation to the total uncertainty in projected yield changes was examined. In simulations without genotypic adaptation, most of the uncertainty came from the climate model parameters. Comparison with the simulations with genotypic adaptation and with a previous study suggested that the relatively low crop parameter uncertainty derives from the observational constraints on the crop parameters used in this study. Fourthly, the simulations were used, together with an observed dataset and a simple analysis of crop cardinal temperatures and thermal time, to estimate the potential for adaptation using existing cultivars. The results suggest that the germplasm for complete adaptation of groundnut cultivation in western India to a doubled- $\mathrm{CO}_{2}$ environment may not exist. In conjunction with analyses of germplasm and local management practices, results such as this can identify the genetic resources needed to adapt to climate change.
\end{abstract}

KEY WORDS: Adaptation · Climate change impacts $\cdot$ Crop growth model $\cdot$ General circulation model Resale or republication not permitted without written consent of the publisher

\section{INTRODUCTION}

Increase in global mean temperature is often used as a metric for climate change. Key synthesis reports such as those commissioned by national governments (Schellnhuber et al. 2006, Stern 2007) and that of the Intergovernmental Panel on Climate Change (IPCC, Parry et al. 2007) often summarise the impacts of climate change using global or local mean temperature as the independent variable. Stern (2007, Chap. 3) have collated and suggested functional forms for the response of climate-sensitive sectors to rising temperature. The form of their agricultural production curve is inverse parabolic, and the authors note that tropical regions may already be past the maximum in that response. The model results collated and plotted by Easterling et al. (2007) suggest a similar result, with most tropical yields falling in response to any temperature increase, and many mid- to high-latitude yields rising or remaining constant at 1 to $3^{\circ} \mathrm{C}$ of warming and falling beyond that. Falling yields in response to mean temperature increases are also beginning to be seen in direct observations (Lobell \& Field 2007).

In the case of annual food crops, there is both a theoretical and observational basis for the above response when local temperatures are used as the independent 
variable. The ascending part of the yield response curve could be due to more rapid rates of growth at progressively warmer temperatures. As temperature increases, 2 processes begin to be important: a decline in the net rate of photosynthesis will reduce growth rates, and biomass accumulation will start to be limited by shorter crop durations (e.g. Squire 1990, Nigam et al. 1994). This second process is governed in part by the optimum temperature for development of the crop $\left(T_{0}\right)$, which influences the time to maturity (i.e. the duration of the crop). Note that this temperature is not usually the optimum for biomass or yield. The response to mean temperature can differ according to whether temperatures are above or below $T_{0}$ : for some crops, increases in temperature to super-optimal values can result in a lengthening of the time to maturity and an increase in yield; if temperatures remain suboptimal, then duration and yield decrease. This mechanism has been shown to be important under climate change (Challinor et al. 2007) through assessments examining the full range of relevant climate-crop processes (crop response to $\mathrm{CO}_{2}$, temperature extremes, water stress etc.).

The response of an annual crop to climate change in India was further elucidated by the study of Challinor \& Wheeler (2008a), which assessed the importance of mean temperature in the context of the inherent uncertainties of crop simulation. The present study builds on this work by including climate simulation uncertainty in order to provide a more holistic assessment of the importance of this process. By including also genotypic variation in the response to mean temperature, the present study aims to provide a preliminary estimate of the likelihood that existing germplasm (i.e. currently used crop varieties) can be used to adapt to mean temperature changes (Section 3.2). The primary focus is on temperatures that remain sub-optimal for development, since there is greater consensus on the response of crops at these temperatures (Challinor \& Wheeler 2008a), and since the response of crops to super-optimal temperatures has been modelled elsewhere (Challinor et al. 2007).

Studies of the response of crops to climate often quantify the uncertainty from the climate model (e.g. Challinor et al. 2005b, Baigorria et al. 2007) or the crop model (Katz 2002, Makowski et al. 2006, Challinor \& Wheeler 2008b), but rarely both. Comprehensive assessment of uncertainty in climate simulation is difficult due to the computational expense of climate models, the difficulty in assessing structural and parameter uncertainty, and issues relating to the probabilistic interpretation of results (e.g. Collins 2007). The climate ensemble used in the present study quantified only parameter uncertainty. Crop parameter uncertainty was assessed using a similar method; unlike Challinor
\& Wheeler $(2008 \mathrm{a}, \mathrm{b})$, structural uncertainty (i.e. variation in results across crop models) was not considered. Whilst this restricts the simulation domain used, it ensures that the ranges in crop yield resulting from climate and crop parameter perturbations are comparable. The second objective of the study is therefore to examine the relative contribution of uncertainty in crop and climate simulation to the total uncertainty in yield simulation (Section 3.3). Preliminary work on this was carried out by Challinor et al. (2005a), who used 4 of the 53 climate ensemble members used in the present study. The range of temperatures in this climate ensemble provide a further opportunity: to examine the response of yield to changes in temperature and compare these qualitatively to the summary graphs of Stern (2007, Chap. 3) and Easterling et al. (2007).

\section{METHODS}

\subsection{Climate model ensemble}

The climate simulations of Murphy et al. (2004) were used to provide daily input data for the crop model. These climate simulations used HadAM3 coupled to a mixed layer ocean under equilibrium present-day (baseline) and doubled- $\mathrm{CO}_{2}$ conditions. The simulations cover the entire globe at a resolution of $2.5^{\circ}$ latitude by $3.75^{\circ}$ longitude. Climate model parameters were varied relative to the standard (control) set of parameters, by seeking expert opinion on plausible ranges. The 29 parameters chosen by Murphy et al. (2004) for this represent key sub-grid physical processes as either logical switches, variable coefficients or thresholds. Parameters were varied one at a time, with a minimum and maximum value being used for variable coefficients. This procedure resulted in 53 perturbed physics simulations in the baseline climate, and a further 53 in doubled- $\mathrm{CO}_{2}$ climates. The baseline and doubled- $\mathrm{CO}_{2}$ simulations were each run for $20 \mathrm{yr}$, giving a total of $1060 \mathrm{yr}$ of simulated weather. The range of outputs from these simulations capture some of the uncertainty associated with the response of the atmosphere to a doubling of $\mathrm{CO}_{2}$.

\subsection{Study region}

The study region is a single climate model grid cell. Whilst this results in limited sampling of climate across space, this choice means that all variations in output are due to climate and/or crop model perturbations; the results are not confounded by spatial variability. The study region was chosen by searching for a grid cell where temperature increases under doubled- $\mathrm{CO}_{2}$ 
were small enough to lead to a shortening of crop duration, rather than a lengthening (see Section 1). This is the likely situation across most of India under even a relatively high emission scenario (namely SRES A2, simulated using the Hadley Centre climate model; see Challinor \& Wheeler 2008a). This choice also has the advantage that temperatures during anthesis are unlikely to exceed those at which pod-set begins to decline (e.g. Vara Prasad et al. 2000), a process that could further confound results and which has been studied elsewhere (Challinor et al. 2007). For similar reasons, a second criterion was that water stress should be unlikely to change significantly between the baseline and doubled- $\mathrm{CO}_{2}$ simulations. The fully-coupled version of the model used to produce the climate ensembles, HadCM3, produces an intensification of the Indian summer monsoon under doubled $\mathrm{CO}_{2}$ (Turner et al. 2007). A grid cell with low water stress in both scenarios was therefore chosen.

The chosen grid cell is centred on $20^{\circ} \mathrm{N} 75^{\circ} \mathrm{E}$ in the western part of India (see Fig. 1). The majority of the study region is in the state of Maharashtra; some is in Gujarat. Part of this region was evaluated by Challinor et al. (2005b) for seasonal forecasting of groundnut yield. Water in this grid cell was, in most cases, nonlimiting in the baseline climate (rainfall during the simulated growing season averaged $89 \mathrm{~cm}$ across all 1060 simulations, with a standard deviation, $\mathrm{SD}$, of $26 \mathrm{~cm}$ ).

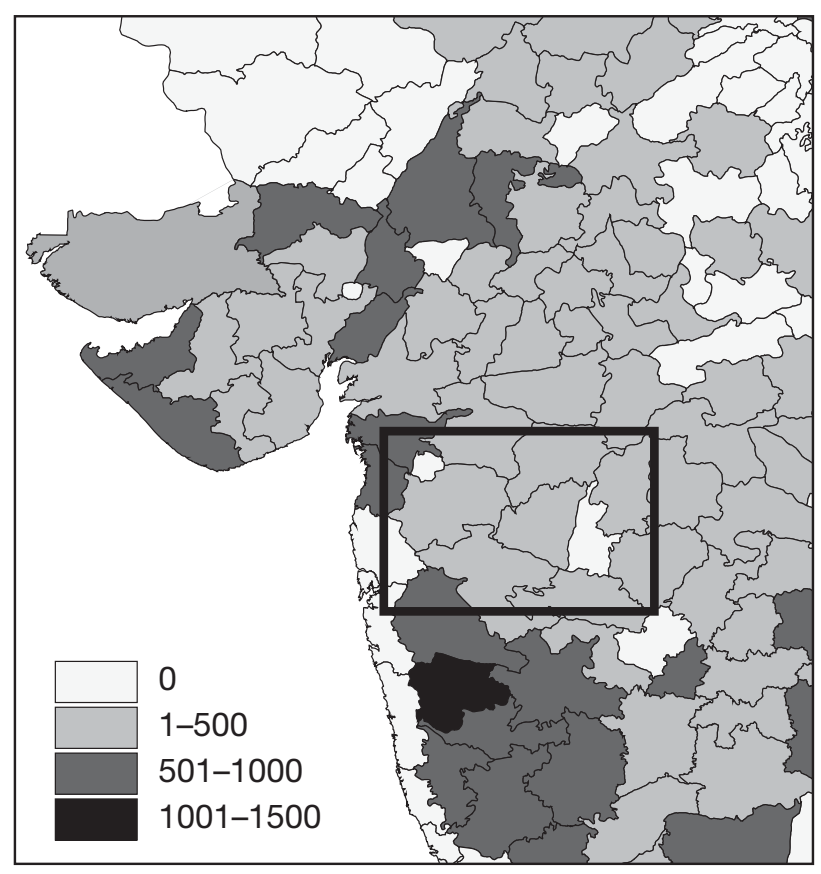

Fig. 1. Study region (grid cell $20^{\circ} \mathrm{N}, 75^{\circ} \mathrm{E}$; western India). Districts are also plotted, with 1966 crop yield $\left(\mathrm{kg} \mathrm{ha}^{-1}\right)$ shown by shading. 0: no available data or no groundnut grown
However, some small values of precipitation did occur, the smallest being $9.7 \mathrm{~cm}$. The doubled- $\mathrm{CO}_{2}$ simulations had a mean growing season precipitation of $101 \mathrm{~cm}$, with an SD of $30 \mathrm{~cm}$ and a minimum value of $31 \mathrm{~cm}$. Only 7 of the 53 ensemble members showed a decrease in 20 yr mean precipitation. Depending on the subseasonal distribution of rainfall, flooding could be a hazard in some of these years. However, this issue is not explored here. Subseasonal variability could also lead to water stress in some years, and this is captured by the simulations. Mean seasonal temperatures across all baseline and doubled- $\mathrm{CO}_{2}$ simulations were 23 and $26^{\circ} \mathrm{C}$ respectively, both with a SD of $0.9^{\circ} \mathrm{C}$. The full ranges of seasonal mean temperatures encountered were 17.8 to $28.5^{\circ} \mathrm{C}$ (baseline) and 23.8 to $32.4^{\circ} \mathrm{C}$ (doubled $\mathrm{CO}_{2}$ ).

Groundnut Arachis hypogaea L. has been identified as an under-researched crop that, in South Asia, is both important to food security and vulnerable to climate change (Lobell et al. 2008). It is a common crop within the study region (Challinor et al. 2003), and a well-tested crop model and parameter set exist for this crop (see Section 2.3). District-level yield and growing area data, which are essential for model calibration, were taken from the database of agricultural returns for the period 1966 to 1989 compiled by the International Crops Research Institute for the Semi-Arid Tropics (ICRISAT) in Patancheru, India. Fig. 1 shows the districts in and around the study region. A district was assigned to the study region if any part of the district fell within the region. The time series of pod yield for each individual district was linearly detrended to 1966 levels in order to remove the influence of improved varieties and management methods (i.e. technology). Mean yield for the study region was obtained by weighted averaging of mean 1966 to 1989 yields, based on both growing area within the district and the area of the district within the region. This method, used due to the absence of more precise data, assumes that the area under cultivation in each year was distributed evenly throughout each district. Groundnut varieties commonly grown in Maharashtra are JL24, TAG24, JL120, JL220, TG37, SB11, AK159, and GG2. Many of these mature on average in 100 to $110 \mathrm{~d}$ in the monsoon (Kharif) season.

\subsection{Crop model ensemble}

\subsubsection{Overview}

The crop model used was the General Large-Area Model for annual crops (GLAM: Challinor et al. 2004) with the additional parameterisations of Challinor \& Wheeler (2008b) and Challinor et al. (2005c). This is a 
relatively simple process-based model designed to run with daily climate model output. It has been used successfully across India with observed gridded data (Challinor et al. 2004), reanalysis (Challinor et al. 2005d) and direct climate model output (e.g. Challinor et al. 2005b, 2007). GLAM has also been used in other regions in the tropics (e.g. Osborne 2005, Challinor et al. 2006, Chee-Kiat 2006). The model contains a multilevel soil water balance that simulates runoff, evaporation, drainage and root uptake. It has a daily time step and uses daily inputs of maximum and minimum temperature, solar radiation and rainfall. Photosynthesis is simulated using transpiration efficiency and transpiration is calculated according to the method of Priestley \& Taylor (1972). The rate of development, and ultimately the time to maturity, is determined using thermal time relations (i.e. growing degree days, which are a sum of daily temperatures). Two modifications were made to the model in order to increase realism. (1) The introduction of terminal drought harvest: whilst for most years water stress is not likely to exert a major control on yield in the study region, it may do in some years (see Section 2.2). (2) A reduction of transpiration efficiency at high temperature to simulate reduced photosynthesis. Both of these modifications, which contribute to the second release version of GLAM, are described in Appendix 1.

The planting window, soils data and parameter sets for the crop yield ensemble were those of Challinor \& Wheeler (2008b). In that study, the range of responses of groundnut to baseline and doubled $\mathrm{CO}_{2}$ was simulated by perturbing parameters relating to transpiration efficiency, water use and specific leaf area. Observations from free air $\mathrm{CO}_{2}$ enrichment (FACE) and controlled environment studies were then used to select simulations for further analysis. Specifically, simulations of the doubled- $\mathrm{CO}_{2}$ environment were rejected if they fell outside of observed ranges (for elevated $\mathrm{CO}_{2}$ ) of yield, specific leaf area and leaf area index. This left 18 ensemble members, each with its own parameterisation of crop response to doubled $\mathrm{CO}_{2}$. Fewer baseline parameter sets were used (4), reflecting the greater uncertainty in crop response under elevated $\mathrm{CO}_{2}$.

In the present study, each of these parameter sets (18 for doubled $\mathrm{CO}_{2}$ and 4 for the baseline simulations) was run with 2 different settings of the new terminal drought stress parameterisation (see Appendix 1) and with the new parameterisation turned off. Each parameter set was run with all 20 yr of data from each of the 53 ensemble members. This resulted in $12720(53 \times 20 \times 4 \times 3)$ baseline simulations and $57240(53 \times 20 \times 18 \times 3)$ simulations under doubled $\mathrm{CO}_{2}$. Additional simulations of adaptation were also performed (Section 2.3.3).
The model was calibrated by adjusting the yield gap parameter as in all previous studies using this model. This parameter accounts for non-climatic determinants of yield. These non-climatic factors contribute to the yield gap, which is the difference between the maximum yield attainable for a given climate and the yields attained in reality. For each member of the full baseline ensemble (i.e. each unique combination of crop and climate parameters), the yield gap parameter was varied in steps of 0.05 across a range of 0.05 to 1 , and a value was chosen that gave a minimum of disagreement between simulated and observed mean yield for the study region. The same uniquely-calibrated values of the yield gap parameter were used in the doubled- $\mathrm{CO}_{2}$ simulations. All cited percentage changes in mean yield refer to the corresponding baseline simulation.

\subsubsection{Crop response to temperature}

The parameters that determine the response to mean temperature (i.e. the cardinal temperatures) are of particular importance given the objectives of this study. The parameter values used here have been used in numerous studies of groundnut in India and have been found to reproduce observed responses well (Challinor et al. 2005c). The durations from the present study are compared to direct observations in Section 3.1. The calibrated and tested thermal time requirement from emergence to maturity is 1565 degree-days, using a base temperature of $10^{\circ} \mathrm{C}$. The calibrated and tested optimum temperature for development $\left(T_{0}\right)$ is $28^{\circ} \mathrm{C}$, which is close to the value used by other studies of groundnut (e.g. Hammer et al. 1995, Bell \& Wright 1998). It is at the lower end of the range for tropical annual crops (Mohamed et al. 1988, Squire 1990). For air temperatures below $28^{\circ} \mathrm{C}$, a higher value of $T_{0}$ would result in the same response of development to temperature change. In this study, only $3 \%$ of the doubled- $\mathrm{CO}_{2}$ simulations had a seasonal mean temperature above $28^{\circ} \mathrm{C}$. However, daily temperatures above this value may have been encountered more frequently. Therefore, as a sensitivity study, a single set of simulations (all $2 \times 53 \times 20$ climates with one crop parameterisation) with $T_{0}=36^{\circ} \mathrm{C}$, near the top of the range for tropical annual crops (Squire 1990, Mohamed et al. 1988), was conducted. This set of simulations provides some indication of the largest likely negative response of duration and yield to temperature increases. Fullycalibrated and tested simulations with a crop with this higher value of $T_{0}$ would be necessary in order to confirm the results from this sensitivity analysis.

As well as the impact of mean temperatures, the response of the crop to temperature extremes was also simulated. GLAM has a set of parameters that deter- 
mine the response of pod-set to high temperature threshold exceedance during anthesis. Sensitivity tests using the calibrated parameter values of Challinor et al. (2005c) showed that the degree of tolerance to these extremes did not alter yield in any of the simulations. Hence, as intended by the design of the study (Section 2.2 ), the influence of high temperatures on reproductive organs is likely to be minimal, and so does not need to be considered in interpreting the results. The third key influence of elevated temperature on the crop acts on transpiration efficiency, as outlined in the Appendix.

\subsubsection{Simulation of adaptation}

In the doubled- $\mathrm{CO}_{2}$ simulations described above, time to maturity was less than the baseline values, due to the higher temperatures. In addition to these noadaptation simulations, genotypic adaptation to mean temperatures was simulated by running all doubled$\mathrm{CO}_{2}$ simulations again with altered thermal time requirements (temperature increases of 10 and $20 \%$ ). These changes lengthened the duration of the crop relative to the no-adaptation simulations.

\subsection{Genotype characterisation data}

Data on crop duration were used to compare the changes in thermal time requirement in the simulations to existing germplasm (Table 1). These data were also compared to the simulated durations for the baseline climate. Data were collected over the period 1976 to 2007 at the research site at ICRISAT $\left(18^{\circ} \mathrm{N} 78^{\circ} \mathrm{E}\right)$, where annual rainfall is approximately $750 \mathrm{~mm}$. The experiments were conducted during the monsoon season (June to September). The accessions characterised were from a range of geographic regions, spanning all areas in which groundnut is cultivated. Each year, the crop was planted in $4 \mathrm{~m}$ rows on ridges $60 \mathrm{~cm}$ apart. Plant-to-plant distance was $10 \mathrm{~cm}$ for fastigiata

Table 1. Crop duration for the range of accessions characterised at the International Crops Research Institute for the Semi-Arid Tropics (ICRISAT) research site

\begin{tabular}{|cc|}
\hline Duration $(\mathrm{d})$ & No. of accessions \\
\hline$<90$ & 3 \\
91 to 100 & 19 \\
101 to 110 & 4144 \\
111 to 120 & 3463 \\
121 to 130 & 4340 \\
131 to 140 & 308 \\
141 to 150 & 11 \\
\hline
\end{tabular}

(Spanish and Valencia) types and $15 \mathrm{~cm}$ for hypogaea (Virginia) types. The experiments received $375 \mathrm{~kg} \mathrm{ha}^{-1}$ of diammonium phosphate at the time of field preparation. At the time of flowering, the crop received $500 \mathrm{~kg}$ gypsum ha ${ }^{-1}$. The experiments were kept free from infestation of pests and weeds. The crop was irrigated with $5 \mathrm{~cm}$ of water 5 to 7 times during the growing season.

The calculated range of values of thermal time requirement in existing germplasm is based on the characterisation data and the following assumptions: the time from planting to maturity is determined using basic thermal time relations, applied using seasonmean temperature, $(\bar{T})$. The use of $\bar{T}$ results in the same crop duration as would the use of daily temperatures. Thus

$$
\theta=\left(\bar{T}-T_{\mathrm{b}}\right) D \text { for } p t \bar{T}<T_{0}
$$

where $\theta$ is the thermal time requirement of the crop, $D$ is the crop duration in days, and $T_{\mathrm{b}}$ is the base temperature below which the crop does not develop towards maturity. If the principal control over duration comes from genetic response rather than interannual variation in temperature (e.g. Ntare et al. 2001), and if temperatures do not exceed $T_{0}$, then normalised (i.e. percentage) variations in thermal time requirement equal the associated normalised variations in duration. The upper limit of thermal time requirement available in the germplasm, expressed as a fraction of the thermal time requirement of the currently-cultivated crop, is then given by

$$
\frac{\theta_{\max }}{\theta_{\text {cur }}}=\frac{D_{\text {max }}}{D_{\text {cur }}}
$$

where subscript max refers to the observed maximum and subscript cur refers to the currently-cultivated crop. This equation links parameter changes in the simulations (lefthand side) to observed crop behaviour (righthand side). As well as using this equation to facilitate comparison between direct observation and simulation, Section 3.2 uses Eq. (1) to estimate the sensitivity of $\theta_{\max } / \theta_{\text {cur }}$ to the choice of cardinal temperatures.

\section{RESULTS AND DISCUSSION}

\subsection{Crop yield ensemble}

Analysis of the results focusses on the effect of temperature on season duration. The influence of temperature extremes is small, as outlined in Section 2.

Crop durations in the baseline simulations averaged $123 \mathrm{~d}$ with an SD of $9 \mathrm{~d}$. This is near the centre of the range of observed durations at the ICRISAT research site (Table 1). The observed yield for the grid box, 
derived by weighted averaging, was $685 \mathrm{~kg} \mathrm{ha}^{-1}$. The average simulated yield across the full ensemble was $683 \mathrm{~kg} \mathrm{ha}^{-1}$. Fig. 2 compares the district-level observed yields with the (grid cell) simulations. The observed yields show a larger range than the simulated yields, despite the inclusion of crop and climate uncertainty in the simulations. Possible reasons for this include a potential under-estimation of the interannual variability in yield by GLAM (Challinor et al. 2004) and the lack of simulation of the sub-grid variability that is contained in the district-level yield data. A third reason may be related to the technology trend (see Section 2.2). Without detrending, the simulated and observed yields are not directly comparable, since the model does not simulate the technology trend. With this trend removed, many low and zero values are found in observations; they are not seen in the simulations. Other forms of detrending may produce different results that are less skewed towards low values. With or without detrending, the results underestimate the occurrence of low yields in this location. This is not a general property of the crop model, since it has been successfully used to simulate low yields and crop failure with other input weather data in India (Challinor et al. 2004, 2005b).

The full ensemble of changes in yield between baseline and doubled- $\mathrm{CO}_{2}$ environments are presented in Fig. 3. The no-adaptation case is shown together with adaptation by increasing thermal time requirement by 10 and $20 \%$. Only in the latter case is it likely that a reduction in yield will be avoided. The range of values

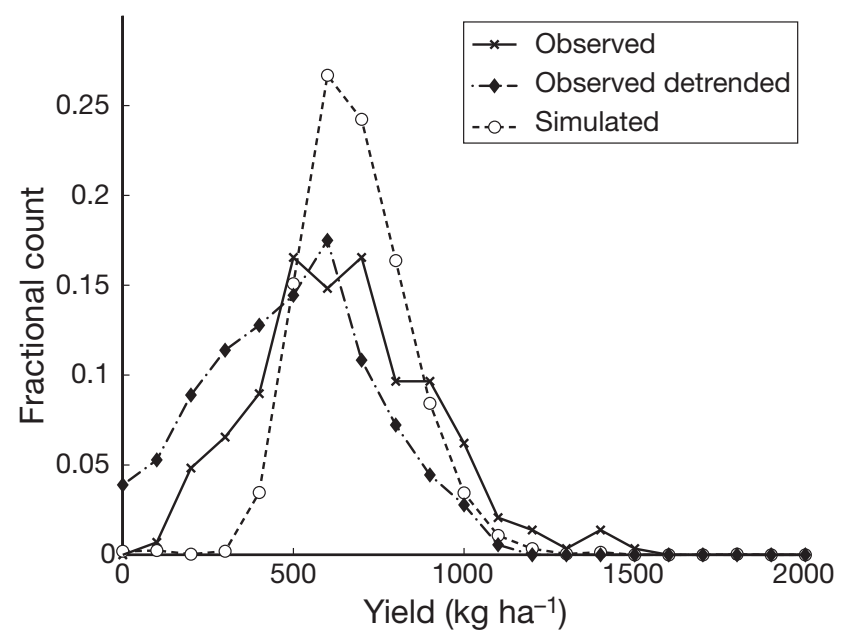

Fig. 2. Normalised frequency plot of observed, observed detrended (to 1966 levels) and simulated crop yield. Observed values include agricultural returns from all districts with any land in the study region, during the $20 \mathrm{yr}$ period from 1966 (totalling 290 data points). Simulated values include $20 \mathrm{yr}$ of baseline climate in 53 climate ensemble members for each of 12 crop parameterisations (12 720 data points)

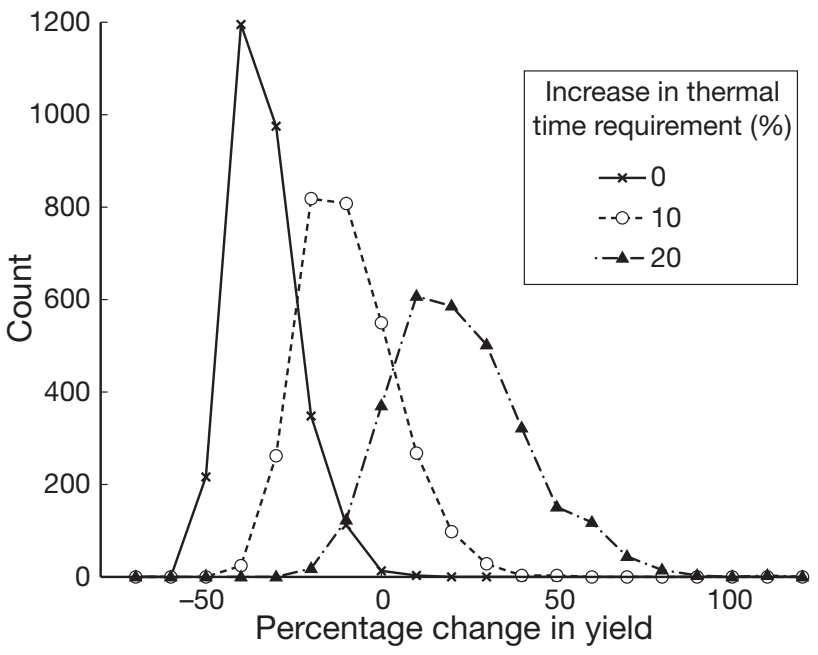

Fig. 3. Frequency plot of change in mean simulated yield from baseline to doubled- $\mathrm{CO}_{2}$ climate. All data are based on $10 \%$ bins. Three sets of simulations are shown: 0,10 and $20 \%$ increases in thermal time requirement. Each set of simulations consists of 53 climate ensemble members for each of 54 crop parameterisations (2862 data points)

of percentage change in yield is large in all 3 cases, reflecting the uncertainty in both crop and climate response to a doubling of $\mathrm{CO}_{2}$. This range increases as thermal time requirement increases. In the sensitivity study with $T_{0}=36^{\circ} \mathrm{C}$, a $20 \%$ increase in thermal time requirement still gave significant negative changes in yield. Simulations with a $30 \%$ increase showed very few negative changes.

Differences in the widths of the curves in Fig. 3 could be due to variations in either crop or climate response to elevated $\mathrm{CO}_{2}$. In order to investigate this, Fig. 4 presents ensembles of yield changes with single climate or crop parameterisations and no change in thermal time requirement. The ensembles with one single crop parameterisation look alike and are also similar to the full ensemble. This suggests that a representative yield ensemble can be determined by using any single crop parameterisation with all climate ensemble members. In contrast, the same curve with a $20 \%$ increase in thermal time requirement (Fig. 5) shows that neither ensembles based on single crop parameterisations nor single climate parameterisations are representative of the full ensemble.

Fig. 6 shows the response of yield to the increases in mean growing season temperature found in the climate model ensemble. The results do not show a monotonic decrease in yield with increasing temperature. Temperature increases above approximately $3.5^{\circ} \mathrm{C}$ can show increases in yield relative to lower temperature increases. The reason for this is illustrated by the colour of the symbols, which indicates changes in season-total 


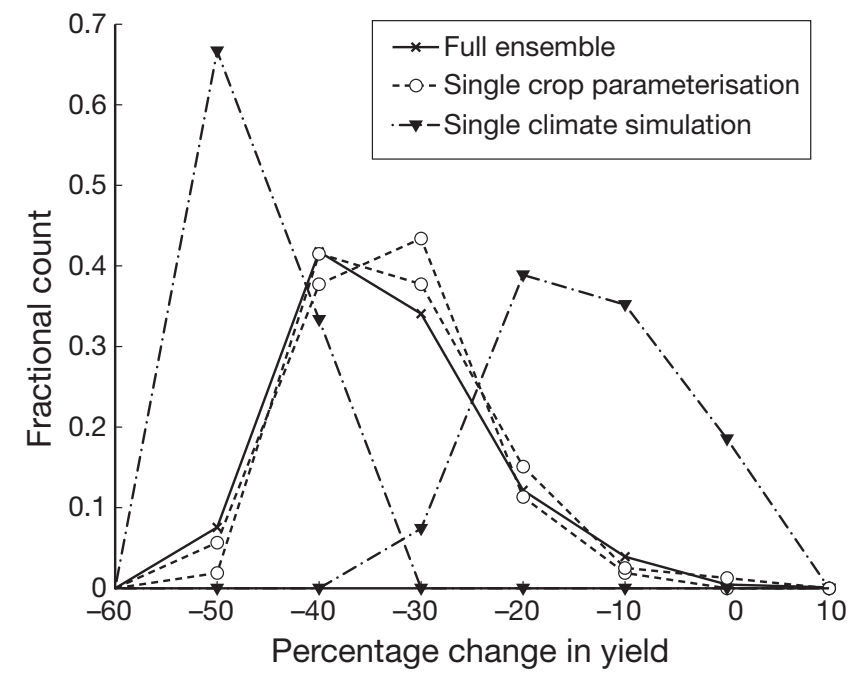

Fig. 4. Frequency plots of change in mean simulated yield from baseline to doubled- $\mathrm{CO}_{2}$ climate, with no increase in thermal time requirement. All data are based on $10 \%$ bins. The solid line shows the full ensemble (as in Fig. 3). Four subsampled ensembles are also shown, 2 using all climate ensemble members with a single crop parameterisation, and 2 using all crop parameterisations with a single climate simulation. These were chosen from the many possible subsamples by noting the bin in which each curve peaked, then choosing curves that peaked at the lowest and highest changes in yield. Where this process did not uniquely define a curve, a single curve was chosen at random from the subset

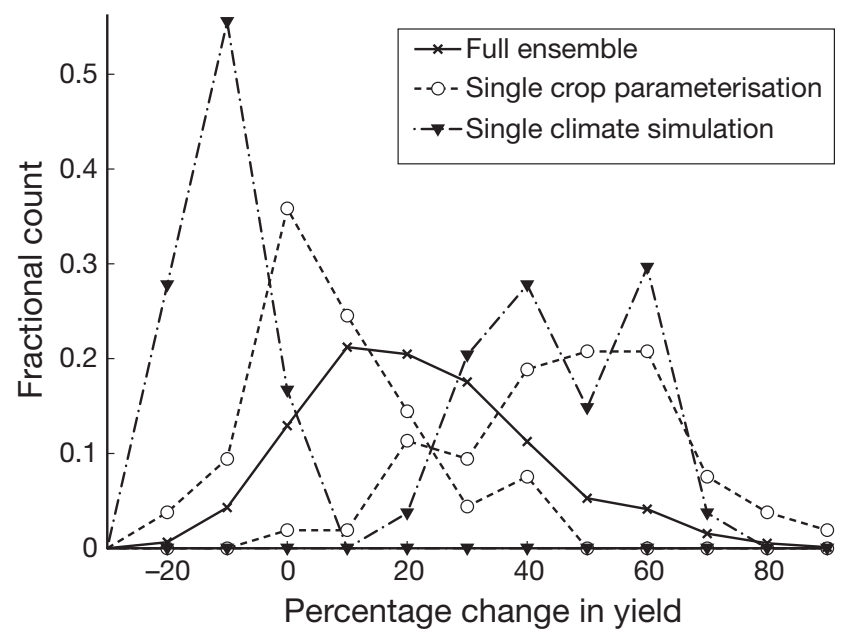

Fig. 5. Frequency plots of change in mean simulated yield from baseline to doubled- $\mathrm{CO}_{2}$ climate, with a $20 \%$ increase in thermal time requirement. All data are based on $10 \%$ bins. The solid line shows the full ensemble (also shown in Fig. 3). Four subsamples of the full ensemble are also shown, using the same procedure as in Fig. 4

net radiation between baseline and doubled- $\mathrm{CO}_{2}$ environments. None of the symbols above $3.5^{\circ} \mathrm{C}$ are blue, and many are red, showing that decreases in solar radiation are small relative to the comparable simulations at smaller temperature changes. For some of the simulations, particularly those with temperature increases greater than $6^{\circ} \mathrm{C}$, there is a second mechanism: crop duration is lengthened in response to mean temperatures exceeding the optimum temperature for development. Since only a very small number of simulations had seasonal mean temperatures above $T_{0}$ (see Section 2.3), this mechanism is unlikely to have been the dominant one. To check this, Fig. 6 was replotted using symbol colours to differentiate total crop duration (not shown). Most of the points between 3.5 and $4.5^{\circ} \mathrm{C}$ showed decreases in duration in the highest tercile (whilst those above $6^{\circ} \mathrm{C}$ showed increases in duration). Hence, despite the reduction in duration and in transpiration efficiency (Eq. A2) for temperatures between between 3.5 and $4.5^{\circ} \mathrm{C}$, yields were similar to those found at lower temperatures. The strong influence of solar radiation is consistent with low water stress (Section 2.2) since it implies a high degree of cloudiness.

\subsection{Adaptation to mean temperature change}

The calculated minimum increase in thermal time requirement to ensure no yield losses under doubled $\mathrm{CO}_{2}$ was 20 to $30 \%$ (Section 3.1). An alternative estimate of the increase in thermal time requirement to ensure no yield losses can be derived by calculating the increase in thermal time requirement needed for crop duration to remain constant between baseline and doubled- $\mathrm{CO}_{2}$ climates. This assumes that increases in assimilation will at least compensate for any negative influences on yield, such as reduced humidity (see Challinor \& Wheeler 2008a). Since this method does not require crop simulation, it can form the basis of a more broadly applicable analysis, which considers a range of values of the cardinal temperatures, rather than just the calibrated values for groundnut used in the simulations. Applying Eq. (1) twice, once for the currently-cultivated crop with thermal time requirement $\theta_{\text {cur }}$ and once for the adapted crop with thermal time requirement $\theta_{\mathrm{a}}$, gives

$$
\frac{\theta_{\mathrm{a}}}{\theta_{\mathrm{cur}}}=\frac{\overline{T_{\mathrm{cd}}}-T_{\mathrm{b}}}{\overline{T_{\mathrm{cb}}}-T_{\mathrm{b}}} \text { for } \overline{T_{\mathrm{cd}}}<T_{0}
$$

where $\overline{T_{\mathrm{cb}}}$ is the mean seasonal temperature in the baseline climate and $\overline{T_{\mathrm{cd}}}$ is the mean seasonal temperature in the doubled- $\mathrm{CO}_{2}$ climate. This equation was applied to each individual ensemble member and repeated with 2 values of $T_{\mathrm{b}}\left(8\right.$ and $11.5^{\circ} \mathrm{C}_{i}$ see Mohamed et al. 1988) and $T_{0}\left(28\right.$ and $36^{\circ} \mathrm{C}_{\text {; see Section }}$ 2.3). The results, presented in Table 2 , give mean values of $\theta_{\mathrm{a}} / \theta_{\text {cur }}$ in the range 1.22 to 1.29 , suggesting a similar increase in thermal time requirement to the ensemble crop simulations. However, values as high as 


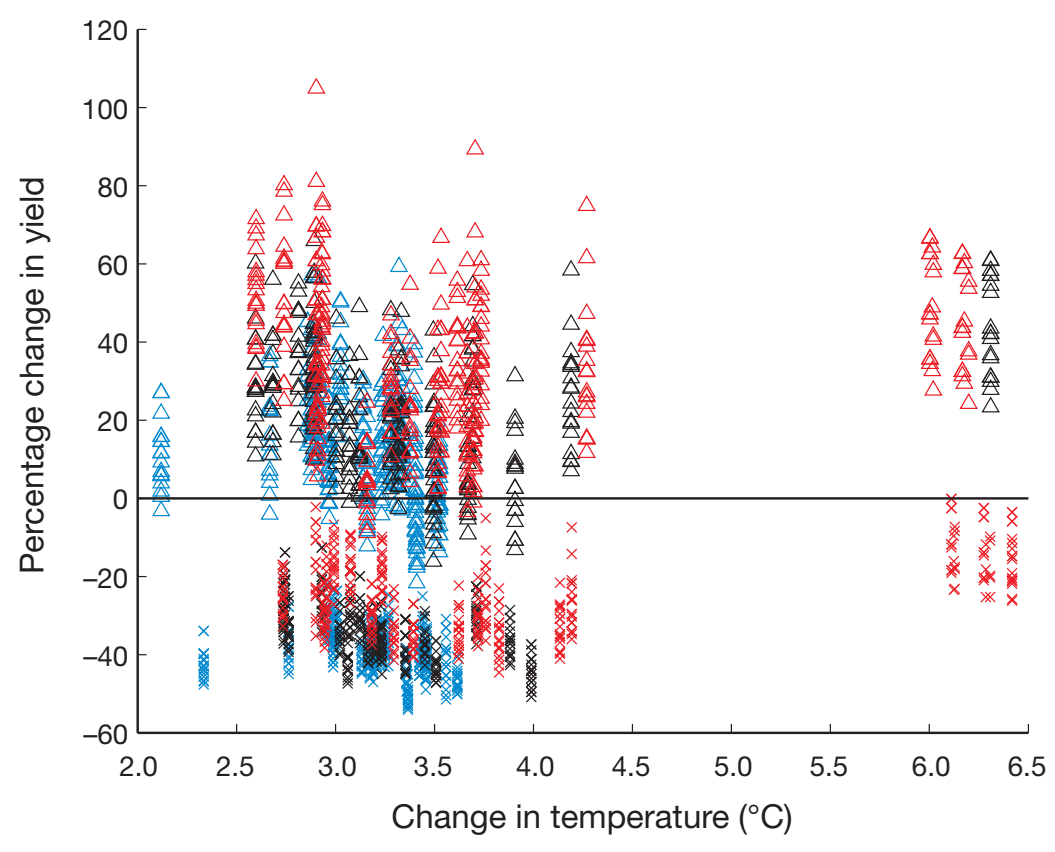

Fig. 6. Change in mean simulated yield from baseline to doubled- $\mathrm{CO}_{2}$ climate from the full ensemble, with a $20 \%(\Delta)$ and $0 \%(x)$ increase in thermal time requirement, as a function of increase in mean temperature averaged over the simulated crop duration. Data are split into terciles of absolute change in seasontotal net solar radiation from simulated planting to maturity. In all cases, this change is negative. $\mathbf{\square}$ : largest decrease in radiation; $\mathbf{\square}$ : central tercile; $\mathbf{\square}$ : smallest decrease. The terciles are bounded at 376 and $419 \mathrm{MJ}$ for the simulations with no change in thermal time requirement, and at 69 and $115 \mathrm{MJ}$ for the simulations with a $20 \%$ increase in thermal time requirement

Table 2. Change in thermal time requirement $\left(\theta_{\mathrm{a}} / \theta_{\text {cur }}\right)$ needed for crop duration to remain constant between baseline and doubled- $\mathrm{CO}_{2}$ climates. The statistics of $\theta_{\mathrm{a}} / \theta_{\text {cur }}$ are based on those ensemble members for which mean seasonal temperature is below the optimum temperature for development $\left(T_{0}\right)$. $T_{\mathrm{b}}$ : base temperature

\begin{tabular}{|c|c|c|c|c|c|}
\hline \multicolumn{2}{|c|}{ Model inputs } & \multirow{2}{*}{ Ensemble size } & \multicolumn{3}{|c|}{$\theta_{\mathrm{a}} / \theta_{\text {cur }}$} \\
\hline$T_{\mathrm{b}}$ & $T_{0}$ & & Min & Max & Mean \\
\hline 8 & 28 & 5616 & 1.15 & 1.29 & 1.22 \\
\hline 8 & 36 & 5724 & 1.15 & 1.40 & 1.22 \\
\hline 11.5 & 28 & 5616 & 1.19 & 1.37 & 1.29 \\
\hline 11.5 & 36 & 5724 & 1.19 & 1.51 & 1.29 \\
\hline
\end{tabular}

1.37 to 1.51 (i.e. a 37 to $51 \%$ increase in thermal time requirement) were found in some cases.

The potential increase in thermal time requirement within existing germplasm can be estimated using Eq. 2. Table 1 suggests $D_{\max }=140 \mathrm{~d}$; the number of varieties with durations greater than this is small, which may prevent identification of a variety suitable for the region. A commonly-grown variety in Maharashtra is JL24 (www.ikisan.com/links/ap_groundnut Seed\%20Varieties.shtml), which has a crop duration in the range of 90 to 110 d Freeman et al. (2002).
Using $D_{\text {cur }}=100 \mathrm{~d}$ (see Section 2.2) in Eq. (2) gives a potential increase in thermal time requirement of $40 \%$. However, using $D_{\text {cur }}=123 \mathrm{~d}$, as suggested in Section 3.1, gives a potential increase in thermal time requirement of $14 \%$. Within this very simple analysis, there are significant uncertainties. Neither of the parameters used in the analysis are known with precision. For example, the duration of the varieties currently recommended by the National Research Centre for Groundnut (www.nrcg.res.in) in Maharashtra mature within the broad range 90 to 125 d. Calibration of simulated crop duration based on more precise observations would reduce the uncertainty associated with this analysis.

\subsection{Sources of uncertainty}

In the scenario with no adaptation, the uncertainty in the response of yields to a doubling of $\mathrm{CO}_{2}$ was effectively represented by varying only climate model parameters (Fig. 4). In contrast, an earlier study (Challinor et al. 2005a) found that crop parameter uncertainty contributed significantly to total uncertainty in yields under both present-day and doubled- $\mathrm{CO}_{2}$ climates. That study varied crop model parameters within ranges determined from the literature and from previous studies. The present study linked parameter variations more closely to observations through the evaluation of the parameterisations for doubled $\mathrm{CO}_{2}$ (Challinor \& Wheeler 2008b). This may be one reason for the lack of importance of crop parameter choice in determining the total uncertainty.

In the scenario with adaptation, uncertainty in crop parameters led to a broadening of the range of simulated yields (Figs. 3 \& 5). This could, in part, simply be due to the longer crop duration in these simulations, giving yields more time to diverge. It may also be due to the parameterisations with increased thermal time requirement not having been tested against any observations. Whilst these runs represent a plausible adapted variety, it may be that parameterisations more closely tied to observations would produce narrower ranges. This highlights the broader issue of the domain of applicability of a model: results should be interpreted cautiously where calibration has been followed by use of the model with input values extending beyond the calibration range. In crop modelling, this may 
refer to changes in a range of conditions, from atmospheric composition and farming practises to weather and climate.

\subsection{Sensitivity of yield to temperature}

The synthesis studies of Stern (2007) and Parry et al. (2007) reported a negative response of crop yield to large mean temperature increases (see Section 1). In contrast, the present study finds no such response (Fig. 6). This may be due to the narrower focus of the study, which examined one crop in one region with one crop model. However, a large number of climates were examined, suggesting that the lack of a systematic response to temperature is robust.

Challinor \& Wheeler (2008b) examined the response of crop yield to mean temperature for 3 crop models: GLAM, CROPGRO and QNUT. CROPGRO (Boote \& Jones 1998) is a widely used crop simulation model, and QNUT (Hammer et al. 1995), whilst not currently used widely, formed the base for the legume model template in APSIM (Wang et al. 2002). Fig. 7 presents the results of Challinor \& Wheeler (2008b) with the $x$-axis rescaled to show the change in mean temperature. Differences between the crop models used are discussed in Challinor \& Wheeler (2008b). Here, we simply note that the form of the curve differs between crop models as a result of differences in the response of crop development rate to mean temperature. Also, the

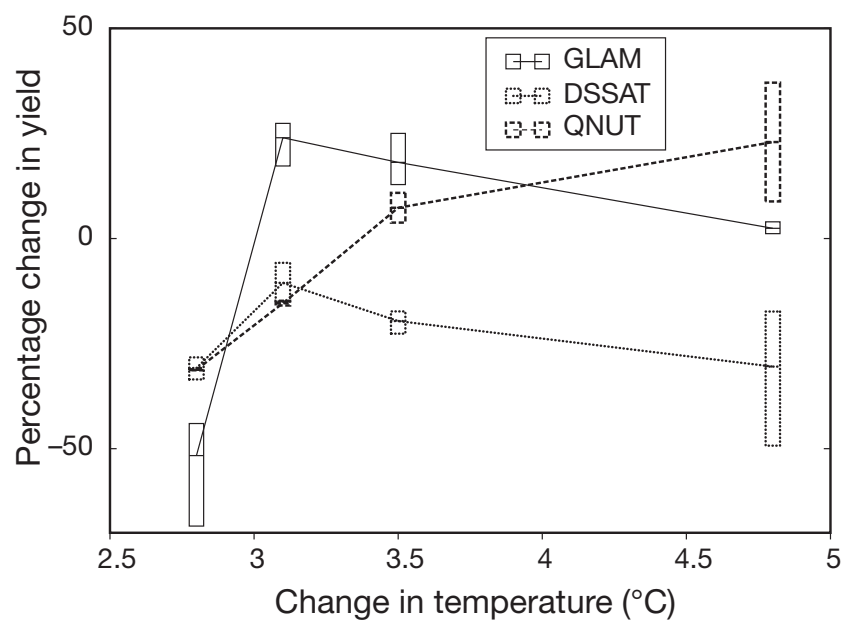

Fig. 7. Change in simulated yield from baseline to doubled$\mathrm{CO}_{2}$ climate from the simulations of Challinor \& Wheeler (2008b). Each box is bounded by maximum and minimum values and has a horizontal line at the mean value. Three models are shown. QNUT is the groundnut model of Hammer et al. (1995) and DSSAT denotes the groundnut version of CROPGRO (Boote \& Jones 1998). The optimum temperature for development is exceeded in all 3 models for the 3 highest temperature increases
GLAM results in Fig. 7 show a different response to that seen in Fig. 6. This is partly due to the fact that mean temperatures exceed $T_{0}$ in a very small fraction of the simulations in Fig. 6, whilst in Fig. 7, 75\% of the simulations exceed $T_{0}$. Whether or not $T_{0}$ is exceeded is clearly an important factor in determining the response of crop yield to temperature change.

\section{CONCLUSIONS}

The results from the present study suggest that the germplasm for complete adaptation of groundnut cultivation in western India to a doubled- $\mathrm{CO}_{2}$ environment does not necessarily exist. However, it is clear that partial adaptation is possible. Further analysis to determine the range of thermal time requirement available in current germplasm would enable a more precise estimate of adaptive capacity. In addition, more robust assessments of adaptive capacity could be carried out by using more than one climate model.

In conjunction with detailed analyses of germplasm (e.g. Badigannavar et al. 2002), local management practices (e.g. Gadgil et al. 1999) and assessment of likely pests and diseases, results such as those presented here can be used to identify the specific genetic resources that are needed to adapt to climate change. The lack of a systematic response of yield to temperature across models (Section 3.4) highlights the need for judicious use of model results and analysis in this endeavour. Both the choice of crop model and the climate affect the form of this curve. In particular, absolute temperature, as opposed to temperature change alone, is important in determining crop yield. The determination of the impacts of climate change on crop yield therefore requires process-based regional modelling. Only through understanding and simulating processes at local and regional levels, and at appropriate levels of complexity, can the impacts of climate change be assessed (Challinor \& Wheeler 2008b). Only by using calibrated models, and by accounting for uncertainty, can robust results be achieved. Simulations should therefore be compared to direct observations as closely and as frequently as possible. When this is done, crop model uncertainty can be minimised, as was demonstrated in Section 3.3. Bayesian statistics may provide a method for reducing uncertainty further (e.g. Arnold et al. 2007) and thus identify with greater precision the genetic resources needed for adaptation.

\section{LITERATURE CITED}

Arnold SR, Methven J, Evans MJ, Chipperfield MP (2007) Statistical inference of $\mathrm{OH}$ concentrations and air mass dilution rates from successive observations of nonmethane 
hydrocarbons in single air masses. J Geophys Res 112 (D10S40),

Badigannavar AM, Kale DM, Murty GSS (2002) Genetic base and diversity in groundnut genotypes. Plant Breed 121: 348-353

Baigorria GA, Jones JW, Shin DW, Mishra A, O'Brien JJ (2007) Assessing uncertainties in crop model simulations using daily bias-corrected Regional Circulation Model outputs. Clim Res 34:211-222

Bell MJ, Wright GC (1998) Groundnut growth and development in contrasting environments 2. Heat unit accumulation and photo-thermal effects on harvest index. Exp Agric 34:113-124

Boote KJ, Jones JW (1998) Simulation of crop growth: Cropgro model. Agricultural systems modeling and simulation. In: Peart RM, Curry RB (eds) Agricultural systems modeling and evaluation. Marcel Dekker, New York, p 651-692.

Challinor AJ, Wheeler TR (2008a) Crop yield reduction in the tropics under climate change: processes and uncertainties. Agric For Meteorol 148:343-356

Challinor AJ, Wheeler TR (2008b) Using a crop model ensemble to quantify $\mathrm{CO}_{2}$ stimulation of water-stressed and wellwatered groundnut. Agric For Meteorol 148:1062-1077

Challinor AJ, Slingo JM, Wheeler TR, Craufurd PQ, Grimes DIF (2003) Towards a combined seasonal weather and crop productivity forecasting system: determination of the working spatial scale. J Appl Meteorol 42:175-192

> Challinor AJ, Wheeler TR, Slingo JM, Craufurd PQ, Grimes DIF (2004) Design and optimisation of a large-area process-based model for annual crops. Agric For Meteorol 124:99-120

Challinor A, Wheeler T, Slingo J, Hemming D (2005a) Quantification of physical and biological uncertainty in the simulation of the yield of a tropical crop using present day and doubled $\mathrm{CO}_{2}$ climates. Phil Trans R Soc B 360(1463): 2085-2094

Challinor AJ, Slingo JM, Wheeler TR, Doblas-Reyes FJ (2005b) Probabilistic hindcasts of crop yield over western India. Tellus 57A:498-512

> Challinor AJ, Wheeler TR, Craufurd PQ, Slingo JM (2005c) Simulation of the impact of high temperature stress on annual crop yields. Agric For Meteorol 135:180-189

Challinor AJ, Wheeler TR, Slingo JM, Craufurd PQ, Grimes DIF (2005d) Simulation of crop yields using the era40 reanalysis: limits to skill and non-stationarity in weatheryield relationships. J Appl Meteorol 44:516-531

Challinor AJ, Wheeler TR, Osborne TM, Slingo JM (2006) Assessing the vulnerability of crop productivity to climate change thresholds using an integrated crop-climate model. In: Schellnhuber J, Cramer W, Nakicenovic N, Yohe G, Wigley TML (eds) Avoiding dangerous climate change. Cambridge University Press, Cambridge, p 187-194

Challinor AJ, Wheeler TR, Craufurd PQ, Ferro CAT, Stephenson DB (2007) Adaptation of crops to climate change through genotypic responses to mean and extreme temperatures. Agric Ecosyst Environ 119:190-204

Chee-Kiat T (2006) Application of satellite-based rainfall estimates to crop yield forecasting in africa. PhD thesis, University of Reading

Collins M (2007) Ensembles and probabilities: a new era in the prediction of climate change. Phil Trans R Soc A 365: 1957-1970 doi:10.1098/rsta.2007.2068

Easterling WE, Aggarwal PK, Batima P, Brander KM and others (2007) Food, fibre and forest products. In: Parry JL, Canziani OF, Palutikof JP, van der Linden PJ, Hanson CE (eds) Climate Change 2007: impacts, adaptation and vul- nerability. Contribution of Working Group II to the Fourth assessment report of the Intergovernmental Panel on Climate Change. Cambridge University Press, Cambridge, p 273-313.

> Ferreyra RA, Pachepsky LB, Collino D, Acock B (2000) Modeling peanut leaf gas exchange for the calibration of crop models for different cultivars. Ecol Model 131:285-298

Freeman HA, der Merwe PJAV, Subrahmanyam P, Chiyembekeza AJ, Kagoungo W (2002) Assessing adoption potential of new groundnut varieties in Malawi. Exp Agric 38: 211-221

Gadgil S, Rao PRS, Rao KN, Savithiri K (1999) Farming strategies for a variable climate. Tech. Rep. 99AS7, CAOS, Indian Institute of Science, Bangalore

Hammer GL, Sinclair TR, Boote KJ, Wright GC, Meinke H, Bell MJ (1995) A peanut simulation model. I. Model development and testing. Agron J 87:1085-1093

Katz RW (2002) Techniques for estimating uncertainty in climate change scenarios and impact studies. Clim Res 20: 167-185

- Lobell DB, Field CB (2007) Global scale climate-crop yield relationships and the impacts of recent warming. Environ Res Lett 2 (014002)

Lobell DB, Burke MB, Tebaldi C, Mastrandrea MD, Falcon WP, Naylor RL (2008) Prioritizing climate change adaptation needs for food security in 2030. Science 319:607-610

> Makowski D, Naud C, Jeuffroy MH, Barbottin A, Monod H, (2006) Global sensitivity analysis for calculating the contribution of genetic parameters to the variance of crop model prediction. Reliab Eng Syst Saf 91:1142-1147

Mohamed HA, Clark JA, Ong CK (1988) Genotypic differences in the temperature responses of tropical crops. J Exp Bot 39:1121-1128

> Murphy JM, Sexton DMH, Barnett DN, Jones GS, Webb MJ, Collins M, Stainforth DA (2004) Quantifcation of modelling uncertainties in a large ensemble of climate change simulations. Nature 430:768-772

Nigam SN, Rao RCN, Wynne JC, Williams JH, Fitzner M, Nagabhushanam GVS (1994) Effect and interaction of temperature and photoperiod on growth and partitioning in 3 groundnut (Arachis hypogaea l.) genotypes. Ann Appl Biol 125:541-552

> Ntare BR, Williams JH, Dougbedji F (2001) Evaluation of groundnut genotypes for heat tolerance under field conditions in a Sahelian environment using a simple physiological model for yield. J Agric Sci 136:81-88

Osborne TM (2005) Towards an integrated approach to simulating crop-climate interactions. PhD thesis, University of Reading

Parry ML, Canziani OF, Palutikof JP and others (2007) Technical summary. Climate change 2007: impacts, adaptation and vulnerability. Contribution of Working Group II to the Fourth Assessement Report of the Intergovernmental Panel on Climate Change, p 23-78. Cambridge University Press, Cambridge

Passioura JB (1983) Roots and drought resistance. Agric Water Manag 7:265-280

Priestley CHB, Taylor RJ (1972) On the assessment of surface heat flux and evaporation using large-scale parameters. Mon Weather Rev 100:81-92

Schellnhuber J, Cramer W, Nakicenovic N, Yohe G, Wigley TML (eds) (2006) Avoiding dangerous climate change. Cambridge University Press, Cambridge

Squire G (1990) The physiology of tropical crop production. CAB International, Wallingford

Stern N (2007) The economics of climate change. The Stern review. Cambridge University Press, Cambridge 
Turner AG, Inness PM, Slingo JM (2007) The effect of doubled $\mathrm{CO}_{2}$ and model basic state biases on the monsoonenso system. I. Mean response and interannual variability. Quart J Roy Meteorol Soc 133:1143-1157

Vara Prasad PV, Craufurd PQ, Summerfield RJ, Wheeler TR (2000) Effects of short episodes of heat stress on ower production and fruit-set of groundnut Arachis hypogaea L. J Exp Bot 51:777-784
Vara Prasad PV, Boote KJ, Hartwell Allen Jr L, Thomas JMG (2003) Superoptimal temperatures are detrimental to peanut (Arachis hypogaea L.) reproductive processes and yield at both ambient and elevated carbon dioxide. Glob Change Biol 9:1775-1787

Wang E, Robertson MJ, Hammer GL, Carberry PS and others (2002) Development of a generic crop model template in the cropping system model apsim. Eur J Agron 18:121-140

Appendix 1. GLAM v. 2.0

\section{GLAM v. 2.0: new parameterisations}

Two new parameterisations were introduced for this study, one relating to water stress and one relating to photosynthesis. Simulated maturity is hastened if the crop is growing into terminal drought, provided that the harvest index is higher than a critical minimum, $H_{\mathrm{I}}^{\mathrm{min}}$. Terminal drought occurs when the potentially extractable soil water is less than a critical minimum, determined by

$$
\theta_{\text {crit }}=\theta_{\mathrm{u}}+\left(\theta_{\text {dul }}-\theta l l\right) F_{\text {sw }}
$$

where $F_{\mathrm{sw}}$, which controls the sensitivity of the crop to terminal drought, has a value of between 0 and $1 . \theta_{\text {dul }}$ and $\theta l l$ are the drained upper limit of the soil and the lower limit, respectively. In the present study, $\left[H_{\mathrm{I}}^{\mathrm{min}}, F_{\mathrm{sw}}\right]$ were set to either $[0.1,0.1]$ or $[0.25,0.01]$, reflecting the uncertainty in these parameters.

The second parameterisation reduces transpiration efficiency $\left(E_{\mathrm{T}}\right)$ at high temperatures to represent reduced photosynthesis. Between temperatures $T_{\text {ter1 }}$ and $T_{\text {ter2 }}, E_{\mathrm{T}}$ is reduced linearly from its non-temperature-limited value of $E_{\mathrm{Tf}}$ to 0 :

$$
E_{\mathrm{T}}=E_{\mathrm{Tf}}\left(1-\frac{T-T_{\text {ter1 }}}{T_{\text {ter } 2}-T_{\text {ter } 1}}\right)
$$

where $T$ is temperature, and in this study $T_{\text {ter } 1}=35^{\circ} \mathrm{C}$ and $T_{\text {ter } 2}=47^{\circ} \mathrm{C}$. These values are based on the experiments and reports of a number of studies, most notably by Ferreyra et al. (2000) and Vara Prasad et al. (2003).

\section{Further code modification}

In addition to the changes outlined above, 2 changes to the code of GLAM were made. The first of these changes is the partitioning of potential evapotranspiration, replacing Eqs. (15) and (16) of Challinor et al. (2004) with

and

$$
E^{\mathrm{e}}=E_{\text {pot }}^{\mathrm{T}} \mathrm{e}^{-\mathrm{kL}}
$$

$$
T_{\mathrm{T}}^{\mathrm{e}}=E_{\text {pot }}^{\mathrm{T}}\left(1-\mathrm{e}^{-\mathrm{kL}}\right)
$$

These new equations result in an increased component of soil evaporation. They reflect correctly the partitioning of energy into evaporation and transpiration. The second change replaces Eqs. (20) and (21) of Challinor et al. (2004) with

$$
\theta_{\mathrm{pe}}=\int_{0}^{z_{\max }}\left(\theta(z)-\theta_{\mathrm{rll}}\right)\left(1-\mathrm{e}^{-\mathrm{k}_{\mathrm{DIF}} \mathrm{l}_{\mathrm{v}}(\mathrm{z})}\right) \mathrm{d} z
$$

which is a more faithful reproduction of the original parameterisation of Passioura (1983)
Editorial responsibility: Mikhail Semenov, Harpenden, UK
Submitted: June 12, 2008; Accepted: October 12, 2008

Proofs received from author(s): January 20, 2009 